\section{Recombinant factor Vlla therapy in a patient on long term anticoagulant treatment with a bleeding and acute subdural hematoma}

\author{
NATAŠA KOVAČ • ALEKSANDAR GOPČEVIĆ • JOSIP KOVAČ • \\ PETAR GAĆINA • MLADEN NOVKOSKI
}

\author{
NATAŠA KOVAČ $(\bowtie) \cdot$ \\ ALEKSANDAR GOPČEVIĆ • \\ JOSIP KOVAČ • MLADEN NOVKOSKI \\ Department of Anesthesiology, \\ University Hospital \\ "Sestre milosrdnice", \\ Zagreb, Croatia \\ Phone: 385/1/2924808 \\ Fax: 385/1/3787428 \\ E-mail: nkovac@inet.hr \\ PETAR GAĆINA \\ Department of Hemathology, \\ University Hospital \\ "Sestre milosrdnice",
}

Zagreb, Croatia

\begin{abstract}
In this paper we report on the successful correction of a coagulopathy with activated recombinant factor seven (rFVIla) therapy which enabled surgical removal of a life threatening subdural hematoma. The severe coagulopathy developed due to long term warfarin therapy, which followed heart valvular reconstruction and replacement. The coagulopathy failed to improve following fresh frozen plasma and vitamin $K$ therapy. Activated recombinant factor VII therapy became the treatment of choice, which enabled the life saving surgical removal of the subdural hematoma.
\end{abstract}

Key words: activated recombinant factor seven, subdural hematoma, anticoagulant therapy, neurosurgery.

\section{Introduction}

Recombinant activated coagulation factor VII (rVIla) has been developed as a suitable way for the treatment of spontaneous and surgical bleeding in patients with congenital and acquired hemophilia with antibodies (inhibitors) against factor VIII (FVIII) and factor IX (FIX) (1). In addition, it is a useful hemostatic agent proven effective in numerous other diagnostic and therapeutic procedures like biopsies in liver disease, thrombocytopenia with bleeding, total hip replacement, etc.(3, $9,10)$. rFVIla induces hemostasis at the site of injury independent of the presence of FVIII and by forming complexes with exposed tissue factor (TF) (1). It bypasses activation of factor $\mathrm{VIII}$ and directly activates factor $\mathrm{X}$ into $\mathrm{Xa}$ and IX into IXa. The natural factor seven (FVII) is a vitamin $\mathrm{K}$ dependent protease primarily synthesized by the liver (4). Therefore, rFVIIa treatment could be effective and clinically protective in hemorrhages and coagulopathies caused by liver dysfunction (4). The long-term anticoagulant, warfarin, decreases circulating levels of vitamin K-dependent coagulation factors and increases the risk of hemorrhagic complications. Intracranial bleeding is one of the most ominous complications of anticoagulant therapy, calling for immediate intervention.

In this paper, rFVIla therapy is described which led to a rapid correction of coagulation system abnormalities and enabled urgently required, life saving surgery.

\section{Case report}

A 35-yr-old woman was admitted to hospital with nausea, vomiting, headache and drowsiness. She was hardly communicative with a GCS 12 and mild left sided weakness. Her pupils were reactive and isocoric. Head CT scan revealed a large hemispheral subdural hematoma with basal tutorial spread. Urgent surgical removal of the hematoma was indicated.

The patient was on long term, prophylactic, oralanticoagulant therapy with warfarin (6 mg daily) because of valvular heart surgery done 4 years ago. That operation had included the implantation of a tricuspid valve, commissurotomy of the mitral valve, and reconstruction of the aortic valve. The primary cause of the structural disintegration and functional valvular failure had been rheumatic fever in childhood. On admission, the acute coagulopathy was life threatening. The prothrombin time (PV) was 3\% (normal value 70-130\%) and partial thromboplastin time (PTT) was 106 seconds (normal value 26-36 
seconds), thrombin time (TT) was 14 seconds (normal value 14-21 seconds) and fibrinolysis 195, thrombocyte count was $153 \times 10 \mathrm{eg} / \mathrm{L}$. The indicated, urgent, pending surgical procedure posed a high risk for excessive bleeding. Fresh frozen plasma (FFP) $1200 \mathrm{ml}(20 \mathrm{ml} / \mathrm{kg})$ and vitamin $\mathrm{K} 20 \mathrm{mg}$ were administered. Correction of the coagulation parameters was slow. Three hours later, following FFP and vitamin $\mathrm{K}$ administration, the PV still remained too low (34\%). In order to facilitate surgery, with a clinically acceptable PTT, we administered 1,2 mg of rFVIlla intravenously and repeated the same dose two hours later in the operating theatre ( $\mathrm{rFVIIa} \mathrm{-} \mathrm{NovoSeven} \mathrm{produced}$ by Novo Nordisk A/S, Bagsvaerd, Denmark). The coagulation parameters improved quickly reaching a PV $124 \%$ and PTT 33 seconds within this short period of time. During the operation no excessive bleeding occurred. The postoperative recovery was smooth and functional status normalized. Control CT scans ruled out any postoperative bleeding and appropriate intracranial structural relations were recorded. At the same time, the induced high PV might have been a risk factor for a thrombotic complication on the artificial heart valve surfaces. In order to continue with anticoagulant prophylaxis, the patient was treated with a continuous heparin infusion and gated to an acceptable PTT (70-80\%). No thrombotic complications occurred in the postoperative period.

\section{Discussion}

Warfarin, a widely prescribed oral anticoagulant, is used for the prevention of primary and secondary venous and arterial thromboembolic complications (6). In the case of our patient, prolonged warfarin therapy was prescribed to prevent thrombi formation, chronic atrial fibrillation and to maintain the mechanical prosthetic heart valves. The most common complication of warfarin use is adverse bleeding. Such therapy caused the acute bleeding and subdural hematoma, which the patient presented with on admission. Since fresh frozen plasma and vitamin $\mathrm{K}$ therapy failed to achieve safe hemostasis, rFVIIa was used to treat the bleeding. This procedure turned out to be very effective. The coagulation parameters improved and normalized promptly. The rapid correction made the urgent surgical procedure possible.

The administered dose of rVIla was given according to the manufacturer's recommendation taking into account the patient's body weight. The recommended doses for patients with hemophilia and alloantibody inhibitors are between $90 \mathrm{mcg} / \mathrm{kg}$ to $120 \mathrm{mcg} /$ $\mathrm{kg}$ (8). Lower doses $15 \mathrm{mcg} / \mathrm{kg}$ to $20 \mathrm{mcg} / \mathrm{kg}$ are shown to procure an adequate hemostasis in patients with other disorders of coagulation (7). Our patient promptly reacted to two repeated doses of $20 \mathrm{mcg} / \mathrm{kg}$.

rFVIla was developed as a new approach to hemophilia treatment. It has been used in various nonhemophilia patients with a few adverse events $(2,3,9)$. Several case reports and small series have reported rFVIla as effective and safe therapy in patients with trauma and abdominal surgery, other surgical indications as well as for some diagnostic procedures $(3,9$, 10). Our report indicates that correction of warfarin induced coagulopathy in neurosurgery may be an additional indication for rFVIla therapy.

\section{Conclusion}

In this paper we reported effective rFVIIa therapy in warfarin induced coagulopathy in neurosurgical patient. The fast improvement of hemostasis and the control of bleeding enabled the life saving neurosurgical operation, when effects of vitamin $K$ and fresh frozen plasma were of limited value.

\section{REFERENCES}

1. Arkin S, Cooper HA, Huntter JJ, et al: Activated recombinant human coagulation factor VII therapy for intracranial hemorrhage in patient with hemophilia A or B with inhibitors. Haemostasis 28:93-98,1998

2. Abu-Hajir M, Hollowell J, Nagaroje G: Managment of 2 patients with subdural hematoma and coagulopathy with recombinant human activated Factor VII. Blood, 98:79b (11 Part 2), 2001 (Abstract)

3. Al Douri M, Shafi T, Al Khudairi D, et al: Effect of the administration of recombinant activated factor VII (rVIla; NovoSeven (R) ) in the management of severe uncontrolled bleeding in patients undergoing heart valve replacement surgery. Blood Coagulation and Fibrinolysis 11 (Suppl 1):S121-S127, 2000

4. Bernstein ED, Jeffers L, Erhardtsen E, et al: Recombinant factor VIla corrects prothrombin time in cirrhotic patients: A preliminary study: Gastroenterology 113:1930-1937, 1997

5. Billion S, Le Niger C, Escoffre-Barbe M, et al: The use of recombinant factor VIla (NovoSeven (R)) in a patient with a factor XI deficiency and circulating anticoagulant. Blood Coagulation and Fibrinolysis $12: 551-553,2001$

6. Deveras RAE, Kessler CM: Recombinant factor VIla (rFVIla) successfully and rapidly corrects the excessively high international normalized ratios (INR) and prothrombin times induced by warfarin. Blood 96 (11 Part 1): 638a, 2000

7. Deveras RA, Kessler CM: Reversal of Warfarin-Induced Excessive Anticoagulation with Recombinant Human Factor VIla Concentrate. Ann Inter Med. 137:884-888, 2002

8. Hender U: Recombinant factor VIla (NovoSeven) as a hemostatic agent. Semin Hematol 38 (4 Suppl 12):43-47, 2001

9. Hendriks GDH, Van der Maaten JMAA, De Wolf J, et al: An Effective Treatment of Severe Intractable Bleeding After Valve Repair by One Single Dose of Activated Recombinant Factor VII. Anesth analg 93:287-289, 2001

10. Kessler C: Hemorrhagic complication of thrombocytopenia and oral anticoagulant: Is there a role for recombinant activated factor VII ?. Intensive Care Med 28 (Suppl 2):S228, 2002 